\title{
Progressive breathlessness in COPD - The role of hyperinflation and its pharmacological management
}

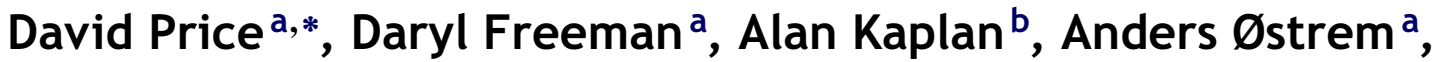 \\ James Reid ${ }^{c}$, Thys van der Molen ${ }^{a}$
}

a Department of General Practice and Primary Care, University of Aberdeen, Foresterhill Health Centre, Westburn Road, Aberdeen AB25 2AY, Scotland, UK

b Chairperson, Family Physician Airways Group of Canada, Richmond Hill, Ontario. Canadg

c Dunedin School of Medicine, University of Otago, Dunedin, New Zealand

Received 23 March 2005; accepted 27 August 2005

Summary Breathlessines, Glong with the associdted onapility to engage in normal activity, is one of the riost distressing y y f to ns copatients with chronic obstructive pulmonary disease (COPD). If treat men ior breathlessness is started early in the disease, physical activity could, in theory, be improved or maintained; this may slow the progression of symptoms towards disability and improve quality of life. A significant cause of breathlessness in COPD is hyperinflation of the lungs due to air trapping, which occurs largely as a result of airflow limitation. Regular exercise reduces the respiratory demand of muscles and, by inference, the impact of air trapping during less intensive activities. Moreover, although airflow limitation in COPD is poorly responsive to anti-inflammatory drugs and less responsive to bronchodilators than in asthma, bronchodilators are clinically proven to bring perceivable symptom improvements in COPD. These improvements correlate with improvements in air trapping indices, which can be significant even in the absence of significant change in forced expiratory volume in 1 second $\left(\mathrm{FEV}_{1}\right)$. The rationale for treatment in COPD, therefore, differs to that for asthma. Understanding of the pathophysiology of COPD improves our chances of achieving an effective intervention with the hope of a better quality of life for patients.

Crown Copyright (c) 2005 Published by Elsevier Ltd on behalf of General Practice Airways Group. All right reserved.

\footnotetext{
* Corresponding author. Tel.: +44 (0) 1224 554588; fax: +44 (0) 1224840683.

E-mail address: d.price@abdn.ac.uk (D. Price).
} 


\section{Contents}

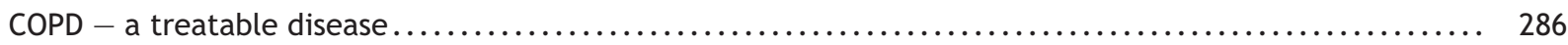

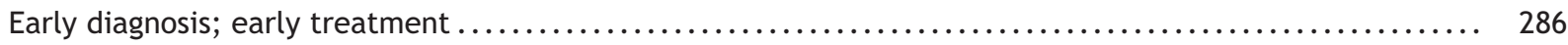

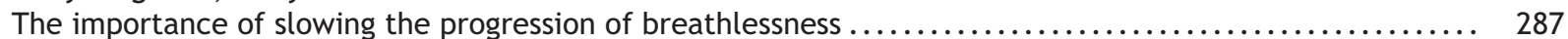

The role of hyperinflation in breathlessness................................................. 287

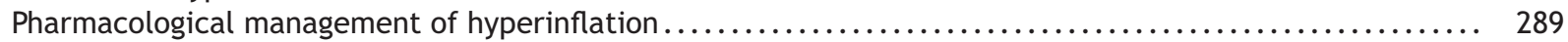

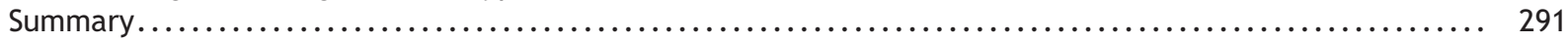

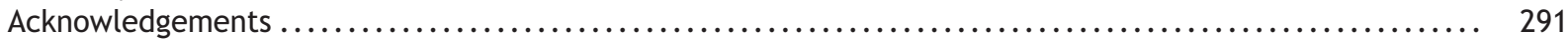

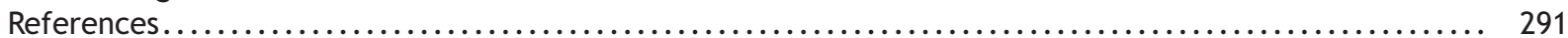

\section{COPD - a treatable disease}

With an estimated 600 million people afflicted worldwide [1], and the prevalence set to increase, chronic obstructive pulmonary disease (COPD) is a common, progressively disabling disease that is predicted to be the third leading cause of death worldwide by 2020 [2]. Although the impact of COPD on patients and health services is considerable [3,4], many physicians take a pessimistic view on the possibilities for effective treatment, especially when compared with asthma, a disease that is less of a burden and much better understood.

This perception possibly stems from inappropriate comparisons of COPD vith asthma. For example, the diagnostif eriterion for COPD-poor forced expiricory volune in 1 second $\left(\mathrm{FEV}_{1}\right)$ that doses hot improve dramaticaly with bronchodilators-can give the Grpression that bronchodilators do little to reduce the impact of the disease, whereas in asthma $\mathrm{FEV}_{1}$ can usually be returned to normal values $[5,6]$.

The concept of poor bronchodilator responsiveness is misleading. Similarly, the pathological mechanisms of COPD, though fairly well defined, are often mistakenly considered to be similar to those of asthma, which in reality has a very different pathological profile [7]. Thus, if the expectation is for COPD to respond similarly to the same treatments as for asthma, it is not surprising that disappointment follows. Furthermore, knowing that smoking is the primary cause of COPD in developed countries (burning biomass fuel in poorly ventilated dwellings is also a major concern in developing countries), some physicians may be less sympathetic to their patients' circumstances and thus have less patience or desire to treat COPD with the same level of commitment as other illnesses - especially if their attention is perceived to make little or no difference to the disease.

Recognized authorities on COPD, such as the Global Initiative for Chronic Obstructive Lung
Disease (GOLD), European Respiratory Society (ERS) and American Thoracic Society (ATS), agree that early treatment of COPD can make a considerable difference to patients in terms of improved healthrelated quality of life $[5,6]$. The single most effective intervention is smoking cessation, which can slow the progressive decline in lung function characteristic of the disease [5,6]. Smoking leads to an unfortunate chemical, behavioural and social addiction, and although difficult, every effort should be made to encourage all patients (particularly those with symptoms of COPD) to stop smoking. Guidelines and resommendations are available for smokirg i $\in$ Sscation programmes $[5,6,8-10]$.

flotier interventions have yet to be shown to reduce the $1 \mathrm{r}$ a of decline in lung function. Hovever; they can considerably impact upon other important treatment goals. Treatments such as bronchodilators or pulmonary rehabilitation help patients to regain and/or maintain levels of activity that they might otherwise slowly lose while adjusting to the symptoms of their disease [11-14]. Thus, treatment presents an opportunity to impact the deconditioning that occurs and may otherwise result in premature disability and reduced quality of life. Appropriate and early intervention is, therefore, key to managing COPD.

The objective of this review is to examine the pathophysiology of COPD with particular emphasis on the influence that lung hyperinflation has on breathlessness (or dyspnoea), and the mechanism through which early treatment with bronchodilators, as recommended by guidelines, can impact the disease through reduced hyperinflation.

\section{Early diagnosis; early treatment}

The characteristic symptoms of COPD are cough, sputum production, and breathlessness upon exertion [5]. Effective initial treatment depends 
upon early diagnosis, particularly with a progressive disease such as COPD, in which the underlying damage starts to develop long before symptoms are noticed by the patient [15]. Even when the early symptoms of COPD are potentially discernable by patients, they may dismiss their symptoms and decline in fitness as an inevitable consequence of ageing [16]. In these cases, patients adapt their lifestyle to avoid more strenuous activities whenever possible. This denial of symptoms may continue for many years before patients present to their general practitioners.

Ideally, screening programmes should be in place in general practice to identify people with earlystage COPD. Currently, depending on the local situation, it may not be feasible or economically possible to screen and monitor all smokers by performing spirometry in general practice. To address this problem, several groups have proposed screening patients via a short symptom-based questionnaire similar to those used to determine the prevalence of COPD in the general population [17-19]. These are currently being refined and are undergoing validation. When completed, these tools should help to identify patients requiring further COPD evaluation, including spirometry, and allow more patients to begin treatment earlier in the disease.

\section{The importance cf slowingtig}

When patients do seek help, it may be because their breathlessness has become intolerable and has a major impact on their daily lives. Early on in the disease, breathlessness may only occur during more strenuous activities. Even at this early stage, however, patients' quality of life can be considerably reduced [20,21]. While the exact cause of this reduction in quality of life is unknown, it is possible that this is partly related to adaptation of lifestyle to avoid strenuous activity. Importantly, the progression of breathlessness and associated activity limitation can be accelerated through a vicious cycle; limitation of activity (or activity avoidance) causes muscular and aerobic deconditioning, which promotes breathlessness at an even lower threshold of activity [5].

Eventually, as the disease progresses, breathlessness becomes so severe that it becomes disabling [5]. The consequent inability of patients adequately to perform daily activities without exhaustion can cause social isolation and depression, severely reducing quality of life.
It is important, therefore, to encourage patients to remain active in order to try to slow the decline in activity and quality of life caused by this avoidable vicious cycle. Treatments that help patients remain active should prolong the time before the disease becomes severely disabling, thus maintaining patients' quality of life for longer.

\section{The role of hyperinflation in breathlessness}

In order to consider appropriate treatment options, it is helpful to understand the underlying mechanisms of breathlessness. The sensation of breathlessness is a complex interplay between mechanical and chemical sensory processes and higher interpretation or perception of these senses [22,23]. The exact relationship between physiological parameters and the global sensory experience is unknown and appears to vary among diseases. In COPD, however, most current theories consider the disproportionate inspiratory effort compared with the actual Jentitation achieved with hyperinflate laungs as a key determinant pr th.outhlessness [24]. Hyperinflation of the lungs causes art if ceased loading of inspiratory musclescand alters the shape of the chest wall and diaphragm, which compromises the efficiency of respiratory muscles due to suboptimal muscle length [24]. Hence, the respiratory muscles are unable to translate increased motor drive signalled from the brain to an adequate inspiration. This neuroventilatory dissociation contributes to the perception of breathlessness.

In normal lungs, the expiratory flow rate is usually sufficient to allow the lungs to empty to the volume of air normally remaining in the lung at the end of expiration during spontaneous breathing - the end-expiratory lung volume (EELV) - before beginning the next inspiration (Figure 1A) [25]. This is normally true even during periods of increased rate of ventilation, such as during exercise. In fact, during periods of increased ventilatory demand, tidal volume can expand through both inhalation and exhalation of greater volumes, thereby increasing the end-inspiratory lung volume (EILV) and lowering EELV (Figure 1A) [24].

The elastic pressure exerted by the chest wall and lungs is a crucial component of breathing. If all respiratory muscles were relaxed, the normal resting pressure of the lungs occurs when the outward elastic recoil of the chest wall equals 


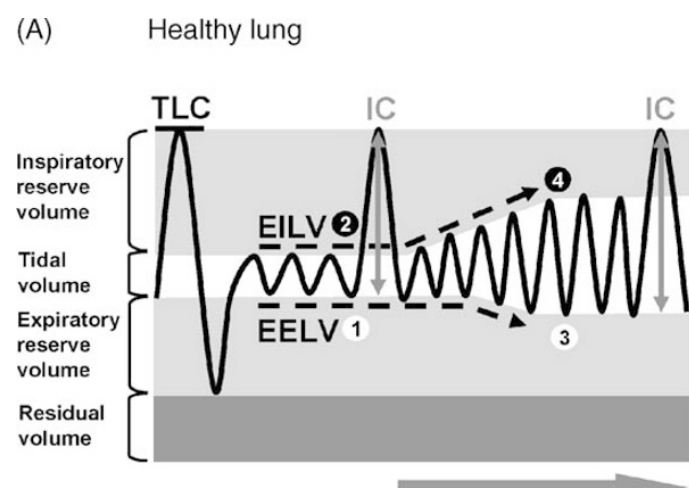

Exercise

(B)

COPD

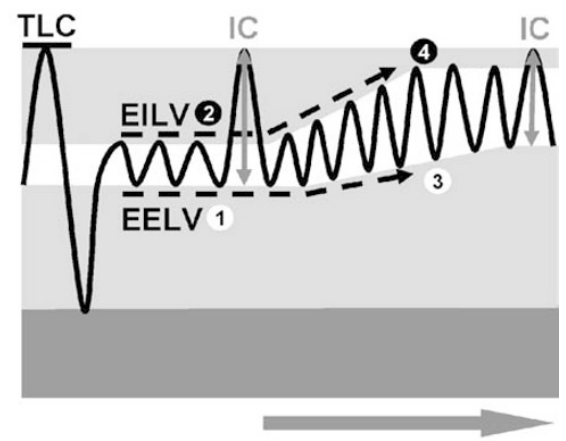

Exercise
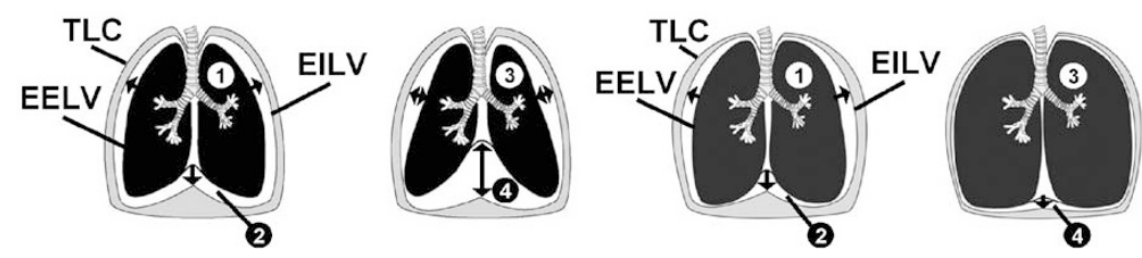

Figure 1 The change in lung volumes during exercise in healthy lungs (A) and COPD (B). TLC, total lung capacity; IC, inspiratory capacity; EELV, end-expiratory lung volume; EILV, end-inspiratory lung volume.

the inward elastic recoil of the lungs $[26,27]$. As the lungs are inflated or deflated, the chest wall and lungs behave differently; hence the point of equilibrium between these two opposing forces does not follow a linear relationship th ro ugh the range of volumes $\sim^{s}$ shovin in Figure 2 , the volume-presuref ielationship is an ' $\mathrm{s}$ '- fol aped curve, wheic greater pressur in ipiratory muscle force) is required to change volume at the extremes of lung volume [27]. Superimposed on these points of pressure equilibrium are the pressure/volume loops for tidal breathing at rest (shaded areas)

(A) Healthy lung

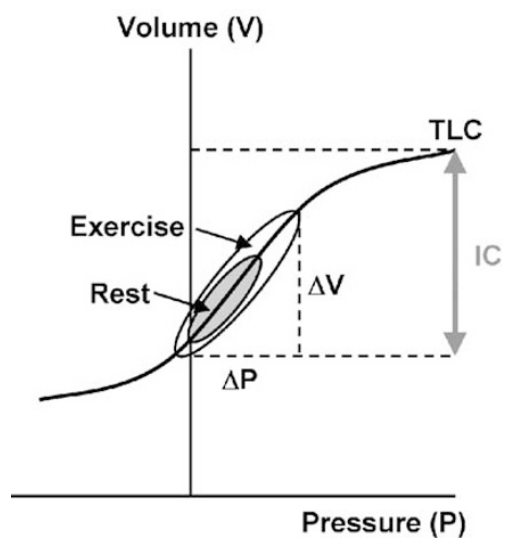

and during exercise (unshaded areas). In healthy lungs, the breathing cycle cocurs on the more linear palit of tine) Curve, both while at rest as well as during exercise (Figure 2A). Hence, pressure change (breathing effort) are normally effidiently converted to change in lung volume [24].

The ventilatory dynamics in COPD are very different because the restriction of expiratory flow causes air to become trapped within the lungs at the end of expiration [24,25,27]. In the early stages of the disease, this occurs as a result

(B) COPD

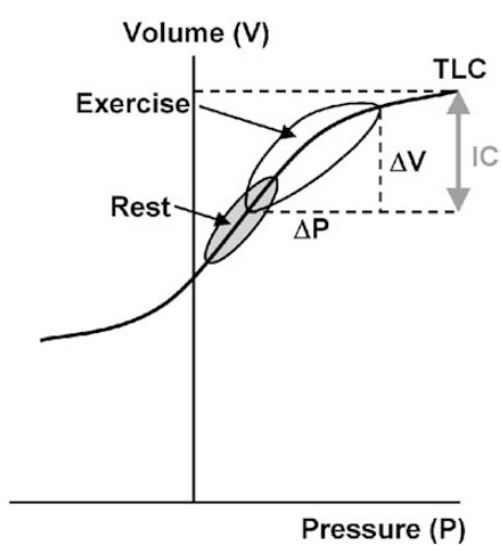

Figure 2 The relationship between lung volume and pleural pressure in healthy lungs (A) and COPD (B). The breathing cycles at rest (shaded area) and during exercise (open area) are shown. TLC, total lung capacity; IC, inspiratory capacity. 
of airflow limitation. Airway narrowing, combined with increased ventilatory demand and increased respiratory rate, may mean that exhalation cannot be fully completed before the next inhalation starts. The progressive air trapping that follows is often referred to as 'dynamic hyperinflation'. In the later stages of the disease, this can be compounded by static hyperinflation due, at least in part, to irreversible structural changes such as loss of alveolar tethering and bullae formation or altered lung mechanics due to loss of lung elasticity [27]. Although 'static hyperinflation' can only be reduced by surgical intervention, such as lung volume reduction surgery [28,29], 'dynamic hyperinflation' can be reduced using interventions that act to improve expiratory airflow - normally bronchodilator therapy.

A degree of progressive air trapping can occur in all obstructive lung diseases, though it is only noticed in asthma during attacks or during exercise $[30,31]$. Similarly, it may go unnoticed during the early stages of COPD except during more demanding physical activity when the respiratory rate increases. The hyperinflation resulting from air trapping forces the breathing cycle to operate at lung volumes closer to the total lung capacity (TLC), as indicated by a reduction in inspiratory capacity (IC) (Figures 1B and 2B). At these high lung volumes, greater pressure changes (inspiettory muscle force) are requireb tor (tess return with respect to volarie charge (Figure 2B: Ufe. ventilatory incíficiency from th resm veritilatory dissociation contributes to breathlessness, the degree of which progressively increases with greater dissociation between the inspiratory muscle force and the volume change. Eventually, this ventilatory inefficiency (and greater required inspiratory muscle force) achieves a level at which intolerable breathlessness is experienced and the patient needs to stop the activity. Intolerable breathlessness will continue until the rate of respiration is reduced (and, therefore, the degree of air trapping) and the breathing cycle returns to lung volumes below the threshold of intolerable breathlessness.

Progressive air trapping can also occur even when patients are at rest, such as in more severe COPD or during exacerbations of COPD. This is partly due to the effect of more severe obstruction. Additionally, however, patients with more severe COPD often have increased rates of ventilation even at rest, due to many factors such as poor gas exchange [24]. Air trapping increases the volume at which the breathing cycle operates until a new equilibrium is restored. The result is that the resting breathing cycle is moved closer to the
TLC and the onset of intolerable breathlessness (Figures 1B and 2B).

\section{Pharmacological management of hyperinflation}

Although smoking cessation is the only proven way to prevent the progressive decline in lung function in COPD, cessation programmes have limited success, even with use of pharmacological aids such as bupropion or nicotine replacement products $[10,32,33]$. Furthermore, although smoking cessation programmes may have considerable impact on individuals, it will be years before even the most effective smoking cessation regimens have an impact on mortality in the population [34]. In developing countries, smoke exposure due to cooking over open fires is difficult to eradicate. There remains, therefore, a need for other interventions in COPD that deliver an immediate benefit to keep patients active in their daily lives. In addition, patients who feel better may feel well enough to consider stopping smoking, providing the potential for a positive feedback tioop.

When considering the tink between hyperinflation and ore ainlessness, a mechanistic goal| Go COPD treatment constitutes lowering the breathing cielaway from the onset of into erabe oreathlessness (or indeed, any degree of breathlessness). Regular exercise training, whether with a pulmonary rehabilitation programme or independently, conditions the muscles and reduces the ventilatory demand of exercise [35]. In COPD patients, this increases the degree of physical exertion tolerated before air trapping begins to drive lung volumes towards inefficient magnitudes. As long as the patient remains active, a positive cycle exists in that the patient is capable of training at more demanding physical activity, thereby gaining greater benefit from rehabilitative training. In this respect, impressive improvements in exercise tolerance and reduction in activity-induced breathlessness have been obtained in clinical trials with intensive rehabilitation exercise programmes [36]. Reduced respiratory demand also underlies the rationale for supplementary oxygen during activity in more severe patients $[37,38]$.

Another approach to reducing air trapping is to reduce the impact of airflow limitation. In some patients, improvements have been achieved through assisted ventilation by such methods as breathing low viscosity air mixture (such as Heliox [39]) or by non-invasive positive pressure ventilation [40]. Pharmacological methods, 
Table 1 Inflammation in COPD and asthma.

\begin{tabular}{|c|c|c|}
\hline & COPD & Asthma \\
\hline Inflammatory cells & $\begin{array}{l}\text { Neutrophils } \\
\text { Mild eosinophilia (not degranulated) } \\
\text { Predominantly CD3, CD8 }\left(T_{C}\right), \text { CD68, } \\
\text { CD25, VLA-1 and HLA-DR +ve } \\
\text { Macrophages ++ }\end{array}$ & $\begin{array}{l}\text { Marked eosinophils }\left(\mathrm{ED}^{+} \text {, }\right. \\
\text { degranulated) } \\
\text { Mast cells } \\
\text { Predominantly CD3, CD4 }\left(\mathrm{T}_{\mathrm{h}} 2\right) \text {, } \\
\text { CD25 (IL-2R) +ve } \\
\text { Macrophages + }\end{array}$ \\
\hline $\begin{array}{l}\text { Inflammatory mediators } \\
\text { and cytokines }\end{array}$ & $\begin{array}{l}\mathrm{LTB}_{4} \text {, TNF- } \alpha \\
\text { IL-8, GRO- } \alpha, \text { GM-CSF protein } \pm \mathrm{IL}-4 \\
\text { but not IL- } 5 \\
\text { Oxidative stress }+++\end{array}$ & $\begin{array}{l}\mathrm{LTB}_{4} \text {, histamine } \\
\text { IL-4, IL-5 gene expression } \\
\text { ( } \mathrm{T}_{\mathrm{h}} 2 \text { profile), IL-13 } \\
\text { Eotaxin, RANTES } \\
\text { Oxidative stress + }\end{array}$ \\
\hline Inflammatory effects & $\begin{array}{l}\text { Peripheral airways } \\
\text { Fibrosis ++ } \\
\text { Parenchymal destruction } \\
\text { Airway hyperresponsiveness } \pm \\
\text { Epithelial metaplasia } \\
\text { Bronchial smooth muscle enlarged } \\
\text { mass (small airways) } \\
\text { Basement membrane } \\
\text { variable/normal } \\
\text { Mucus cell metaplasia/hyperplasia } \\
\text { Mucus secretion }+++\end{array}$ & $\begin{array}{l}\text { All airways } \\
\text { Fibrosis + } \\
\text { No parenchymal involvement } \\
\text { Airway hyperresponsiveness +++ } \\
\text { Epithelial shedding } \\
\text { Enlarged mass (large airways) } \\
\text { Basement membrane hyaline + } \\
\text { thickened } \\
\text { Mucus cell metaplasia (debated) } \\
\text { Mucus secretion + }\end{array}$ \\
\hline $\begin{array}{l}\text { Response to } \\
\text { corticosteroids }\end{array}$ & \pm & \\
\hline
\end{tabular}

LT, leukotriene; IL, interleukin; TNF, tumour necrosis factor; $T_{\text {c }}$ cxito: oxi-C-cell, $7_{\mathrm{h}} 2$, T-helper type 2; Adapted from: Barnes P. Chest 2000;117(2):10S-14S; Jeffery P. Chest 2000:117(5) 25is 20.65 .

however, ain to reduce th? Af low limitation without external apparatus.

Multiple components (both reversible and irreversible) contribute to the airflow limitation in COPD. Progressive and irreversible structural changes in small airways and parenchymal tissue, which reduces the elastic recoil of the lung, are caused by inflammation. Although COPD and asthma are both chronic inflammatory lung diseases, there are fundamental differences in their pathology (Table 1) $[7,41]$. These differences have implications for responsiveness to drug treatment; in particular, the inflammation in COPD is largely not responsive to steroid treatment [42]. Hence, guidelines recommend the use of inhaled steroids only in COPD patients with severe $\left(\mathrm{FEV}_{1}<50 \%\right.$ predicted) disease with repeated exacerbations requiring treatment with oral steroids or antibiotics [5,6]. This is in contrast to asthma, where inhaled steroids are the mainstay of treatment to control the disease, but still do not affect the disease outcome [43].

Central to treatment of COPD is bronchodilator therapy. This may seem paradoxical, considering the use of $\mathrm{FEV}_{1}$ reversibility testing as the basis for the differential diagnosis of COPD from asthma. However, guidelines recognise that these drugs improve airflow, reduce breathlessness, reduce exacerbations and improve health status, and so recommend bronchodilators as first-line maintenance therapy $[5,6]$.

The rationale for bronchodilator use in COPD differs from that in asthma. Airway obstruction in asthma is largely due to acute, reversible bronchospasm resulting from various stimuli. In contrast, acute bronchospasm does not have a major role in COPD, in which the pathology that underlies airway obstruction is largely irreversible. There is, nevertheless, a reversible component of airway obstruction - basal tone in airway smooth muscle due to cholinergic stimulation of the vagus nerve [44].

Basal tone exists in both normal airways and the airways of patients with COPD. The bronchoconstrictive effect is, however, disproportionate in the COPD airway because of the geometry of the already narrowed airways $[44,45]$. Similarly, relaxation of basal tone by bronchodilators in COPD can make a considerable difference in COPD, even when the resulting 
change in $\mathrm{FEV}_{1}$ may be modest in comparison with that achieved in asthma. All classes of bronchodilator relax basal tone, although the duration and magnitude of effect can differ by treatment, as do specific mechanisms of action.

Anticholinergics specifically block cholinergic stimulation from the vagus nerve, whereas betaagonists and theophylline act on the smooth muscle. Studies have shown that combining bronchodilators from different classes can provide additive effects compared with the single agents alone [46-50]. Furthermore, combining bronchodilator therapy with pulmonary rehabilitation can yield significantly greater improvements in exercise endurance time, presumably due to the ability to train at a higher intensity of exercise [51]. Therefore, guidelines recommend optimisation of bronchodilation before turning to other agents such as inhaled corticosteroids $[5,6]$. Assessment of the efficacy of bronchodilators in individual patients should not be based solely on spirometric flow parameters, however, since bronchodilators significantly improve parameters of hyperinflation, and where measured, breathlessness, exercise tolerance and health-related quality of life, with or without significant improvements in $\mathrm{FEV}_{1}$ [11-13,52-56]. Hence, response to bronchodilators is bext measured by improvements in those pariterels that are perceivable by thelpatient.

Guidelines 0 Usd est that bronchodilators are the insoreftective and convenient option for maintenance pharmacotherapy in patients with regular symptoms [5,6]. There are two classes of longacting inhaled agents: anticholinergics, which currently only comprise the 24-hour-acting agent tiotropium, and the long-acting beta-agonists salmeterol and formoterol. Both classes of agents have been shown to reduce breathlessness at rest and during exercise, and to increase exercise endurance time in patients with moderate-severe COPD $[12,13,57]$. These improvements correlated closely with parameters of hyperinflation $[12,13]$. In fact, change in resting IC has consistently been found to be the spirometric parameter that correlates best with improved breathlessness during exertion and increased exercise endurance times, supporting a reduction in air trapping as the mechanism by which bronchodilators improve symptoms in COPD [11-13]. For example, tiotropium has been shown to reduce IC significantly over 24 hours, both at rest and during exercise $[12,55]$.

While guidelines recommend long-acting bronchodilators for maintenance therapy in patients with regular symptoms, inhalation of short-acting bronchodilators as needed is currently recommended in earlier stage COPD $[5,6]$. Vigilant monitoring of patients' use of short-acting medications and probing for early signs of reduced activity may help uncover patients who could benefit from earlier intervention (include smoking cessation, long-acting bronchodilator therapy and encouragement to maintain activity). There is increasing debate about earlier intervention with maintenance therapy for COPD patients, and more research is required to determine the merits of such a strategy. What is clear, however, is that optimised bronchodilator therapy is effective in reducing symptoms, increasing tolerance to activity, reducing exacerbations and improving quality of life in COPD - the major goals of COPD treatment.

\section{Summary}

COPD is a treatable and preventable disease, and an understanding of the pathophysiology increases our chances of achiering effective intervention and improving 'our patients' quality of life Ain t trappins and breathlessness are Chatinarins of COPD, and represent the most treatable fornponents of this illness. Treatment vith Oeffective bronchodilators can bring about significant improvements, both in terms of lung mechanics and, more importantly, in terms of perceived outcomes, such as breathlessness, activity levels and, ultimately, quality of life.

\section{Acknowledgements}

All authors contributed equally to the text in terms of concept, ideas, writing and reviewing. David Price additionally co-ordinated the process. The authors would like to thank David Macari PhD for his editorial assistance in the preparation of this manuscript.

\section{References}

[1] World Health Organization. World Health Report 1997: Conquering suffering, enriching humanity. 1997.

[2] Murray CJL, Lopez AD. Alternative projections of mortality and disability by cause 1990-2020: Global burden of disease study. Lancet 1997;349:1498-504.

[3] Mahler DA, Faryniarz K, Tomlinson D, et al. Impact of dyspnea and physiologic function on general health status in patients with chronic obstructive pulmonary disease. Chest 1992;102(2):395-401. 
[4] Sullivan SD, Ramsey SD, Lee TA. The economic burden of COPD. Chest 2000;117:5S-9S.

[5] Global Initiative for Chronic Obstructive Lung Disease. Global strategy for the diagnosis, management, and prevention of chronic obstructive pulmonary disease. Update 2004. http: / / www. goldcopd.com/revised pdf 2004.

[6] Celli BR, MacNee W, committee members. Standards for the diagnosis and treatment of patients with COPD: a summary of the ATS/ERS position paper. Eur Respir J 2004;23:932-46.

[7] Jeffery PK. Comparison of the structural and inflammatory features of COPD and asthma. Giles F Filley lecture. Chest 2000;117(5):251S-60S.

[8] Anderson JE, Jorenby DE, Scott WJ, Fiore MC. Treating tobacco use and dependence: an evidence-based clinical practice guideline for tobacco cessation. Chest 2002;121(3):932-41.

[9] West R, McNeill A, Raw M. Smoking cessation guidelines for health professionals: an update. Health Education Authority. Thorax 2000;55(12):987-99.

[10] The Tobacco Use, Dependence Clinical Practice Guideline Panel Staff, Consortium Representatives. A clinical practice guideline for treating tobacco use and dependence: A US Public Health Service report. JAMA 2000;283(24):3244-54.

[11] O'Donnell DE, Lam MIU, Webb KA. Spirometric correlates of improvement in exercise performance after anticholinergic therapy in chronic obstructive pulmonary disease. Am J Respir Crit Care Med 1999;160(2):542-9.

[12] O’Donnell DE, Flüge T, Gerken F, et al. Effects of tiotropium on lung hyperinflation, dyspnea and exercise tolerance in patients with COPD. Eur Respir J 2004;23(6):832-40.

[13] O'Donnell DE, Voduc N, Fitzpatrick M, Webb KA. Effect of salmeterol on the ventilatory response to exercise in chronic obstructive pulmonary disease. Eur Respir J 2004;24(1):86-94.

[14] ACCP/AACVPR Pulmonary Rehabilication C FGelifies Panel. Pulmonary rehabilitation. $c$ int $1 C$ CAACVPR eviden based guidelina. citest ig $7 ; 112(5): 1363-95$

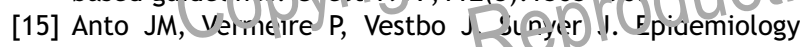
of chronic obstructive pulmonary disease. Eur Respir $\mathrm{J}$ 2001;17(5):982-94.

[16] Price D, Freeman D. The BREATH (Breathlessness Research, Expectations and Treatment hopes) study: findings of a pilot study in four countries. Primary Care Repiratory Journal 2004;11(Supplement 1):s12-4.

[17] van Schayck CP, Loozen JMC, Wagena E, Akkermans RP, Wesseling GJ. Detecting patients at a high risk of developing chronic obstructive pulmonary disease in general practice: cross sectional case finding study. Brit Med J 2002;324:1370-4.

[18] Mullerova H, Wedzicha J, Soriano JB, Vestbo J. Validation of a chronic obstructive pulmonary disease screening questionnaire for population surveys. Respir Med 2004;98(1):78-83.

[19] Price D, Tinkelman RJ, Nordyke S, Isonaka RJ. Utility of a symptom-based questionnaire for identifying COPD in smokers. Am J Respir Crit Care Med 2004;169:A605.

[20] Rennard S, Decramer M, Calverley PMA, et al. Impact of COPD in North America and Europe in 2000: subjects' perspective of Confronting COPD International Survey. Eur Respir J 2002;20:799-805.

[21] Katula JA, Rejeski WJ, Wickley KL, Berry MJ. Perceived difficulty, importance, and satisfaction with physical function in COPD patients. Health Qual Life Outcomes 2004;2(1): 18.

[22] Mahler DA, Jones PW. Measurement of dyspnea and quality of life in advanced lung disease. Clin Chest Med 1997;18(3):457-69.
[23] O'Donnell DE. Breathlessness in patients with chronic airflow limitation. Mechanisms and management. Chest 1994;106:904-12.

[24] O'Donnell DE. Ventilatory limitations in chronic obstructive pulmonary disease. Med Sci Sports Exerc 2001;33(7 Suppl):S647-55.

[25] Pride NB, Milic-Emil J. Lung mechanics. 1995;First(7): 135-60.

[26] Leith DE, Brown R. Human lung volumes and the mechanisms that set them. Eur Respir J 1999;13(2):468-72.

[27] Ferguson $G$. The ins and outs of breathing: an overview of lung mechanics. Eur Respir Rev 2004;13(89):30-4.

[28] Leyenson V, Furukawa S, Kuzma A, Cordova F, Travaline J, Criner $\mathrm{G}$. Correlation of changes in quality of life after lung volume reduction surgery with changes in lung function, exercise, and gas exchange. Chest 2000;118(3):728-35.

[29] Ciccone AM, Meyers BF, Guthrie TJ, et al. Long-term outcome of bilateral lung volume reduction in 250 consecutive patients with emphysema. J Thorac Cardiovasc Surg 2003;125(3):513-25.

[30] Kosmas EN, Milic-Emili J, Polychronaki A, et al. Exerciseinduced flow limitation, dynamic hyperinflation and exercise capacity in patients with bronchial asthma. Eur Respir J 2004;24(3):378-84.

[31] Sciurba FC. Physiologic similarities and differences between COPD and asthma. Chest 2004;126(2 Suppl):117S-24S.

[32] Anthonisen NR, Connett JE, Kiley JP, et al. Effects of smoking intervention and the use of an inhaled anticholinergic bronchodilator on the rate of decline of FEV $_{1}$. JAMA 1994;272(19):1107-505.

[33] Tashkin D, Kanner RE, Bai ey W, et al. Smoking cessation in patients nith or rente obstructive pulmonary disease: a ac anle-bihd, placebo-controlled, randomised trial. Lancet 2001;357(9268):1571-5.

[34] Feen. Cid TI.] Vari Eenugten ML, Hoogenveen RT, Wouters $\mathrm{LF}$, r.utten-van Molken MP. The impact of aging and smoking on the future burden of chronic obstructive pulmonary disease: a model analysis in the Netherlands. Am J Respir Crit Care Med 2001;164(4):590-6.

[35] Maltais F, LeBlanc P, Jobin J, Casaburi R. Peripheral muscle dysfunction in chronic obstructive pulmonary disease. Clin Chest Med 2000;21(4):665-77.

[36] Lacasse Y, Wong E, Guyatt GH, King D, Cook DJ, Goldstein RS. Meta-analysis of respiratory rehabilitation in chronic obstructive pulmonary diseases. Lancet 1996;348: 1115-9.

[37] Report of the Medical Research Council Working Party. Long term domiciliary oxygen therapy in chronic hypoxic cor pulmonale complicating chronic bronchitis and emphysema. Lancet 1981;1:681-6.

[38] Tarpy SP, Celli BR. Long-term oxygen therapy. N Engl J Med 1995;333:710-4.

[39] Palange P, Valli G, Onorati P, et al. Effect of heliox on lung dynamic hyperinflation, dyspnea, and exercise endurance capacity in COPD patients. J Appl Physiol 2004;97(5):1637-42.

[40] Strumpf DA, Millman RP, Carlisle CC, et al. Nocturnal positive-pressure ventilation via nasal mask in patients with severe chronic obstructive pulmonary disease. Am Rev Respir Dis 1991;144(6):1234-9.

[41] Barnes PJ. Mechanisms in COPD. Differences from asthma. Chest 2000;117(2):10S-4S.

[42] Barnes PJ, Ito K, Adcock IM. Corticosteroid resistance in chronic obstructive pulmonary disease: inactivation of histone deacetylase. Lancet 2004;363(9410):731-3.

[43] Global Initiative for Asthma. NHLBI/WHO Workshop Report: Global Strategy for Asthma Management and Prevention - 
Updated April 2002. 2002; Volume NIH Publication No 023659.

[44] Gross NJ, Co E, Skorodin MS. Cholinergic bronchomotor tone in COPD. Estimates of its amount in comparison with that in normal subjects. Chest 1989;96(5):984-7.

[45] Barnes PJ. Managing chronic obstructive pulmonary disease. London: Science Press Ltd., 1999.

[46] COMBIVENT Inhalation Aerosol Study Group. In chronic obstructive pulmonary disease, a combination of ipratropium and albuterol is more effective than either agent alone. An 85-day multicenter trial. Chest 1994; 105(5):1411-9.

[47] Karpel JP, Kotch A, Zinny M, Pesin J, Alleyne W. A comparison of inhaled ipratropium, oral theophylline plus inhaled $\beta$-agonist, and the combination of all three in patients with COPD. Chest 1994;105(4):1089-94.

[48] van Noord JA, de Munck DR, Bantje TA, Hop WC, Akveld ML, Bommer AM. Long-term treatment of chronic obstructive pulmonary disease with salmeterol and the additive effect of ipratropium. Eur Respir J 2000;15(5):878-85.

[49] ZuWallack RL, Mahler DA, Reilly D, et al. Salmeterol plus theophylline combination therapy in the treatment of COPD. Chest 2001;119(6):1661-70.

[50] Cazzola M, Marco FD, Santus P, et al. The pharmacodynamic effects of single inhaled doses of formoterol, tiotropium and their combination in patients with COPD. Pulm Pharmacol Ther 2004;17(1):35-9.
[51] Casaburi R, Kakafka D, Cooper C, Witek J, Kesten S. Improvement in endurance time with the combination of tiotropium and pulmonary rehabilitation in patients with COPD. Chest 2004; Volume in press.

[52] Newton MF, O’Donnell DE, Forkert L. Response of lung volumes to inhaled salbutamol in a large population of patients with severe hyperinflation. Chest 2002; 121(4):1042-50.

[53] Duranti R, Filippelli M, Bianchi R, et al. Inspiratory capacity and decrease in lung hyperinflation with albuterol in COPD. Chest 2002;122(6):2009-14.

[54] Di Marco F, Milic-Emili J, Boveri B, et al. Effect of inhaled bronchodilators on inspiratory capacity and dyspnoea at rest in COPD. Eur Respir J 2003;21(1):8694.

[55] Celli B, ZuWallack R, Wang S, Kesten S. Improvement in resting inspiratory capacity and hyperinflation with tiotropium in COPD patients with increased static lung volumes. Chest 2003;124(5):1743-8.

[56] Tashkin D, Kesten S. Long-term treatment benefits with tiotropium in COPD patients with and without shortterm bronchodilator responses. Chest 2003;123((5):14419.

[57] Liesker JJ, Van De Velde V, Meysman M, et al. Effects of formoterol (Oxis Turbuhaler) and ipratropium on exercise capacity in patients with COPD. Respir Med 2002;96(8):559-66.

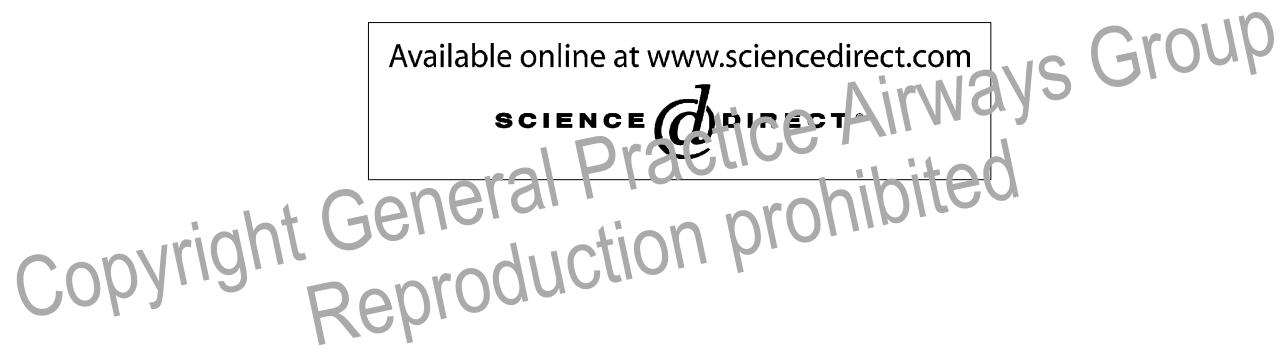

Available online at http://www.thepcrj.com 